\title{
The role of strategic position in brand promise: Evidence from LG Company
}

\begin{abstract}
Ali Eilaghi Karvandi*
Department of Management and Accounting, Kerman Branch, Islamic Azad University, Kerman, Iran

\section{H R O N I C L E}

Article history:

Received January 5, 2016

Received in revised format April

15,2016

Accepted July 1, 2016

Available online

July 4, 2016

Keywords:

Brand promise

Strategic planning

$L G$

Customer
\end{abstract}

\section{Introduction}

During the past few years, there have been strong competition among appliance makers in Iran. The competition was so tight that it was difficult for new competitors to gain any market share and many domestic producers have also disappeared. In such competitive market, it is important for different suppliers to make sure that the consumers trust brand promises. Brand promise is a framework based on which distinct and related experience with brand are recognized for consumer by the enterprise in different times and places and certain situations (Light \& Kiddon, 2009). In a book called Brand Glossary and in definition of Brand Promise, Sieston explained that brand promise could build an image from mutual nature of relationship among the given brand with its users (Swystun, 2006). Brand promises often represent themselves within the framework of products functional characteristics, experiences, feelings, emotions resulting from buying of brand, possession of various personalities against purchase and acquisition of distinct characteristics of products from buying its certain brand (Light \& Kiddon, 2009). There are several studies on the effects of various factors on brand promise.

* Corresponding author.

E-mail address: ali.kervandi@gmail.com (A. Eilaghi Karvandi)

(C) 2016 Growing Science Ltd. All rights reserved. doi: $10.5267 /$ j.msl.2016.7.001 
Samiei Nasr et al. (2014), for instance, made an assessment on the rate of management's interest and personnel's motivation in an Iranian firm named TAM Iran Khodro. The study considered its relationship with fulfilment of firm promises for customers. In their survey, Spearman's correlation coefficient and multiple regressions were used to examine the hypotheses of the survey. They reported that management's tendency and employees' motivation were positively and significantly associated with fulfilment of brand promise.

Abbasi et al. (2014) investigated the effects of four components of organizational culture on brand promise in one of Iranian producers of detergent and sanitary products. They reported that three components of organizational culture including tribal culture, entrepreneurial culture, and market culture could influence positively on brand promise and bureaucratic culture could influence negatively on brand promise. Aziziha et al. (2014) performed a survey on brand promise and reported that there while there was a reverse relationship between two conflict management strategies, cooperation and compromise, and brand promise there was a positive relationship between two conflict management strategies, competition and compromise, and brand promise. Nehzat (2015) investigated the effect of supply chain relationship quality on brand promise and confirmed that communication, cooperation, commitment, independence, adaptability and reliability could positively influence on brand promise.

\section{The proposed study}

This paper presents an empirical investigation to study the effects of various strategies including attribute, advantage, application, consumer, competitive advantage, pricing/quality and category on brand promise for products of LG Company in city of Tehran, Iran. The study designs two questionnaires, one for strategic positioning and the other for brand promise in Likert scale. Cronbach alphas for brand promise and strategic positioning are 0.81 and 0.79 , respectively. Since the population of this survey was unlimited, the study uses the following to calculate the sample size,

$$
N=Z_{\alpha / 2}^{2} \frac{p \times q}{e^{2}},
$$

where $N$ is the sample size, $p=1-q$ represents the probability, $z_{\alpha / 2}$ is CDF of normal distribution and finally $\varepsilon$ is the error term. For our study we assume $p=0.5, z_{\alpha / 2}=1.96$ and $e=0.05$, the number of sample size is calculated as $N=385$. The study has distributed 400 questionnsires to maintain the minimum desirability of the survey.

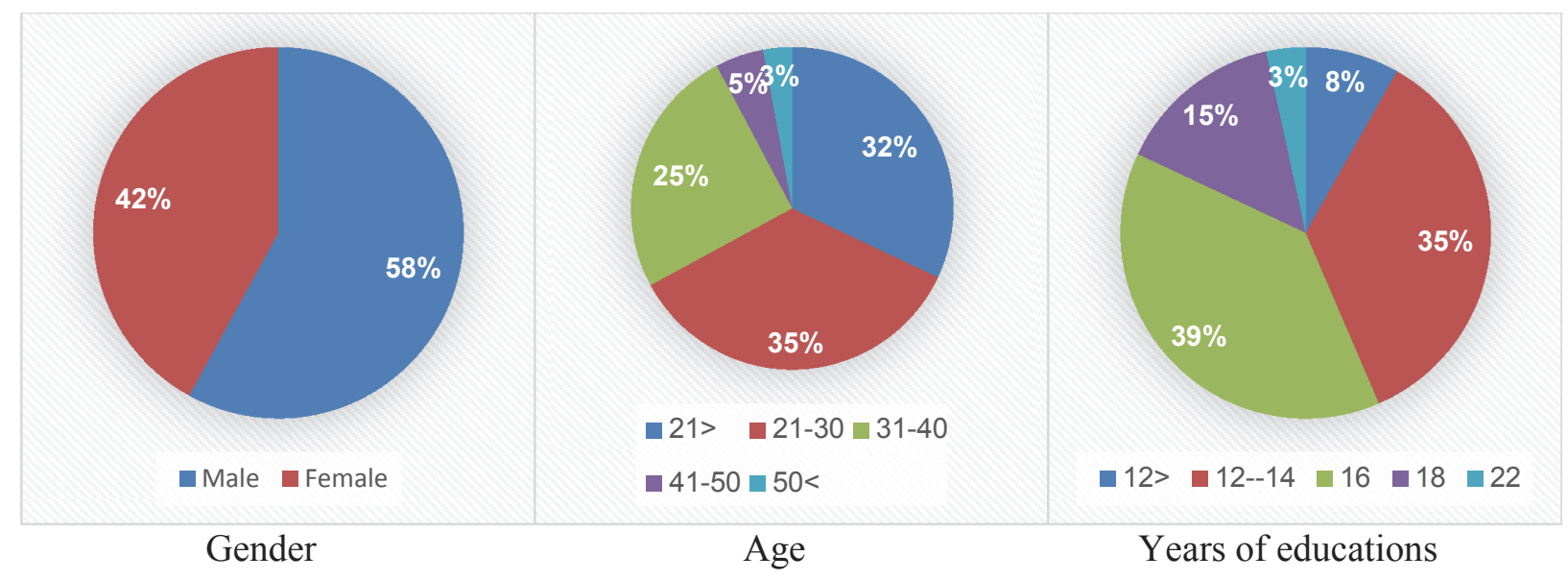

Fig. 1. Personal characteristics of the participants 
As we can observe from the results of Fig. $1,58 \%$ of the participants were male and the remaining $42 \%$ were female. In terms of their age, $67 \%$ of them aged less than 30 and the rest of them were mainly middle aged people and finally, most participants in our survey hold good educational background. Fig. 2 demonstrates the structure of the proposed study,

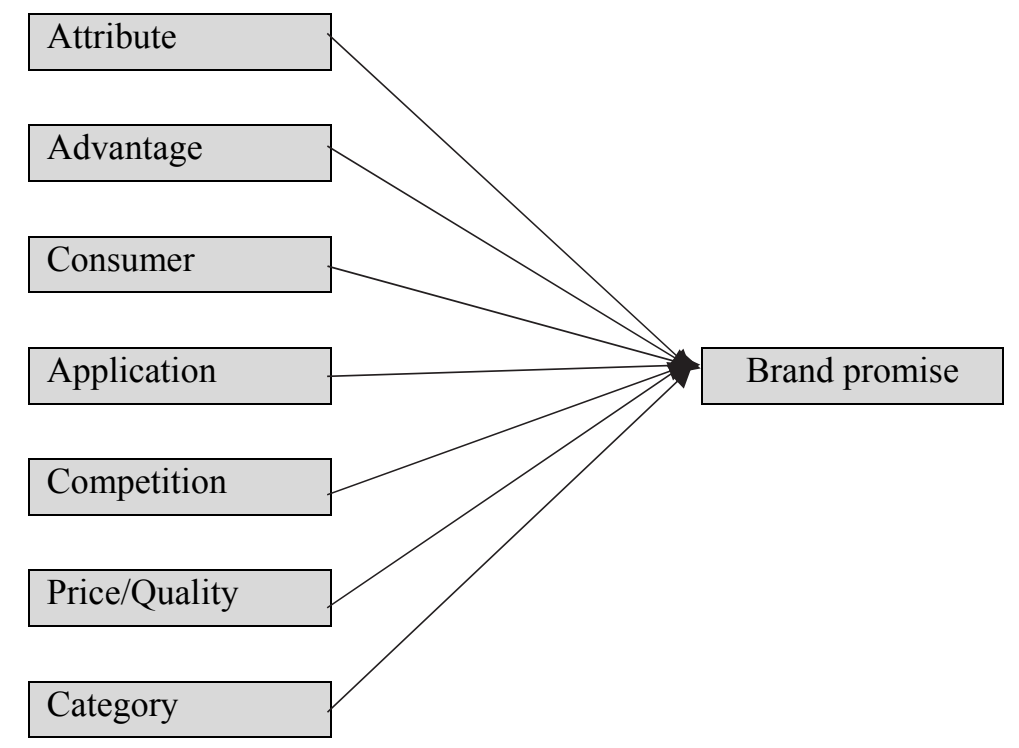

Fig. 2. The structure of different strategies on brand promise

As we can observe from Fig. 2 there are seven hypotheses associated with the proposed study of this paper. The implementation of Kolmogorov-Smirnov test has indicated that the data were not normally distributed and therefore, we use Spearman correlation test to examine the hypotheses of the survey.

\section{The results}

In this section, we present the results of the implementation of Spearman correlation as well as Stepwise regression techniques. Table 1 shows the results of our survey.

\section{Table 1}

The summary of Spearman correlation test

\begin{tabular}{lccc}
\hline Hypothesis & Correlation & Sig. & Result \\
\hline Attribute $\rightarrow$ brand promise & .280 & $0.005^{* *}$ & Confirmed \\
Competitive advantage $\rightarrow$ brand promise & .344 & $0.001^{* *}$ & Confirmed \\
Consumer $\rightarrow$ brand promise & .408 & $0.003^{* *}$ & Confirmed \\
Application $\rightarrow$ brand promise & .326 & $0.0018^{*}$ & Confirmed \\
Competition $\rightarrow$ brand promise & .213 & $0.001^{* *}$ & Confirmed \\
Price/quality $\rightarrow$ brand promise & .462 & $0.001^{* *}$ & Confirmed \\
Category $\rightarrow$ brand promise & .182 & $0.002^{* *}$ & Confirmed \\
\hline
\end{tabular}

*Sig. $<0.05$

$* *$ Sig. $<0.01$

According to the results of Table 1, all hypotheses of the survey have been confirmed and there were positive and meaningful relationships between seven strategies and brand promise. The results have also indicated that price/quality strategy plays the most important role followed by consumer, competitive advantage and application. Table 2 presents the results of Stepwise regression model,

\section{Table 2}


The summary of Stepwise regression

\begin{tabular}{|c|c|c|c|c|c|}
\hline Variable & $\begin{array}{c}\text { Change } \\
\text { coefficient }\end{array}$ & Standard error & $\begin{array}{c}\text { Standard } \\
\text { coefficient }\end{array}$ & t-value & Sig. \\
\hline Intercept & 56.185 & 4.420 & & 12.854 & .000 \\
\hline Price/Quality & .570 & .230 & .411 & 2.762 & .004 \\
\hline Consumer & .510 & .200 & .350 & 2.319 & .000 \\
\hline Application & .460 & .150 & .314 & 2.208 & .011 \\
\hline
\end{tabular}

As we can observe from the results of Table 2, price quality has maintained the highest positive impact on brand promise followed by consumer and application.

\section{Conclusion}

During the past few years, there have been strong competition among appliance makers in Iran. The competition was so tight that it was difficult for new competitors to gain any market share and many domestic producers have also disappeared. In this paper, we have presented an empirical investigation to find out the effects of different strategies on brand promise for one of well-known South Korean suppliers of appliances in city of Tehran, Iran. The study has implemented Spearman correlation and Stepwise regression to examine the effects of seven strategies on brand promise. Using Spearman correlation test, the study has indicated that price/quality strategy played the most important role followed by consumer, competitive advantage and application. Moreover, the implementation of Stepwise regression technique has confirmed that price quality has maintained the highest positive impact on brand promise followed by consumer and application. In today's industrial environment, the created value added along with trade name and brand are not normally placed in position of totally distinctive values (Kotler \& Pfoertsch, 2007). We hope the present study could shed light on how to build a brand in Iranian society by concentrating more on quality along with price.

\section{Acknowledgement}

The authors would like to thank the anonymous referees for constructive comments on earlier version of this paper.

\section{References}

Abbasi, H., Abbasi, H., Faraji, A \& Hajirasouliha, M. (2014). Investigating the effects of organizational culture on brand promise. Management Science Letters, 4(5), 1039-1042.

Aziziha, H., Mousavi, S., Tabatabaee, S \& Khodsetan, A. (2014). Investigating the effect of different conflict management strategies on brand promise: A case study of banking industry. Management Science Letters, 4(1), 1-4.

Kotler, P., \& Pfoertsch, W. (2007). Being known or being one of many: the need for brand management for business-to-business (B2B) companies. Journal of Business \& Industrial Marketing, 22(6), 357-362.

Light, L., \& Kiddon, J. (2009). Six rules for brand revitalization. Learn how companies like McDonald's can reenergize their brands, Arcature LLC.

Nehzat, F. (2015). The impact of supply chain relationship quality on brand promise. Uncertain Supply Chain Management, 3(2), 141-146.

Samiei Nasr, M., Mahmoudzadeh, S., Mousavi, S \& Boostani, A. (2014). The role of management's tendency and personnel's motivation in fulfillment of brand promise. Management Science Letters, 4(6), 1077-1084.

Swystun, J. (Ed.). (2006). The brand glossary. Palgrave Macmillan.

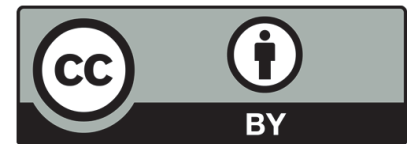

(C) 2016 by the authors; licensee Growing Science, Canada. This is an open access article distributed under the terms and conditions of the Creative Commons Attribution (CC-BY) license (http://creativecommons.org/licenses/by/4.0/). 